\title{
3-DIMENSIONAL GEOMETRIC SURVEY AND STRUCTURAL MODELLING OF THE DOME OF PISA CATHEDRAL
}

\author{
D. Aita*, R. Barsotti*, S. Bennati*, G. Caroti**, A. Piemonte** \\ *Dipartimento di Ingegneria Civile e Industriale - Sezione Strutture \\ **Dipartimento di Ingegneria Civile e Industriale - Sezione Vie, Trasporti e Geomatica \\ Università di Pisa, Largo Lucio Lazzarino 1, 56122 PISA, phone 050221 7770, e-mail gabriella.caroti@ unipi.it
}

\section{Commission II}

KEY WORDS: Structural analysis, Laser scanning, Photogrammetry, Cultural Heritage, Dome

\begin{abstract}
:
This paper aims to illustrate the preliminary results of a research project on the dome of Pisa Cathedral (Italy). The final objective of the present research is to achieve a deep understanding of the structural behaviour of the dome, through a detailed knowledge of its geometry and constituent materials, and by taking into account historical and architectural aspects as well. A reliable survey of the dome is the essential starting point for any further investigation and adequate structural modelling. Examination of the status quo on the surveys of the Cathedral dome shows that a detailed survey suitable for structural analysis is in fact lacking. For this reason, high-density and high-precision surveys have been planned, by considering that a different survey output is needed, according both to the type of structural model chosen and purposes to be achieved. Thus, both range-based (laser scanning) and image-based (3D Photogrammetry) survey methodologies have been used. This contribution introduces the first results concerning the shape of the dome derived from surveys. Furthermore, a comparison is made between such survey outputs and those available in the literature.
\end{abstract}

\section{INTRODUCTION}

The dome of Pisa Cathedral is a stonework of great interest for many aspects related to history, architecture, building techniques and structural behaviour. As an adequate documentation on the dome construction process is missing, the dome has been a matter of discussion from the historical and architectural point of view (Supino, 1913; Salmi, 1938). Some scholars have doubted that the dome could have been built as part of the original cathedral fabric, since its elliptical plan and pointed profile are unique in the coeval Roman architecture (Sanpaolesi, 1959a; Smith, 1984); furthermore, close examination of its technical details and masonry properties is very difficult (Peroni, 1995a). Nonetheless, it is commonly accepted that it can be reasonably dated as early as the 12th Century (Sanpaolesi, 1959b).

The present research project has started by taking advantage of the opportunity provided by the scaffolding recently assembled for the under-way restoration works, in preparation for the $900^{\text {th }}$ anniversary of the Cathedral consecration. This privileged context, also thanks to the cooperation of the Opera della Primaziale Pisana, allowed for a thorough examination of the dome, covering its building details, material properties and the state of preservation of the intrados and extrados surfaces.

It is worthy to note that the dome shows some clearly detectable cracks, already reported by Sanpaolesi during his repairs of 1957. These damages were not considered serious with reference to the global stability conditions of the system formed by the dome and drum (Sanpaolesi, 1959c). The possibility to closely examine the dome is a precious occasion to assess its mechanical behaviour and safety factor with reference to a collapse condition.

The final objective of this research is to perform the investigation of the structural response of the dome, through a detailed knowledge of its geometry and constituent materials, and by taking into account historical and architectural aspects as well. The planned structural analysis aims to develop different structural models, based both on finite elements and simplified analytical approaches.

A reliable survey of the dome is obviously an essential basis for any further investigation and adequate structural modelling. In fact, a different survey output is needed, according both to the type of model chosen and purposes to be achieved, as explained in the next paragraph.

In order to obtain the different models needed for the structural analysis, it was necessary to plan high density and precision surveys. Thus, both range-based (laser scanning) and imagebased (3D Photogrammetry) survey methodologies have been used. Integration of these two methods allows achieving models with density and accuracy requirements both for geometry and radiometry.

In this work, the results obtained in this preliminary step of the research will be presented. In particular, this first stage will focus on the survey of the dome intrados, by underlining some significant aspects and possible future insights.

\section{MATERIALS AND METHODS}

This section presents the final objective of the present research, i.e. to describe the structural dome behaviour according to Finite Element Method (FEM) and analytical models. The absence of surveys characterized by high-density and precision is pointed out, through a brief examination of the status quo on the surveys of the Cathedral dome. A detailed survey aimed to the structural analysis is then acknowledged as a first step to achieve the research purposes. The surveys methods are described, i.e. range-based modelling and image-based modelling. 


\subsection{Structural analysis}

The dome of the Cathedral has an elliptical plan and a pointed profile. It is extremely interesting in that it constitutes an original solution, from an architectural as well as structural point of view.

In this research, the structural analysis of the dome will be performed as the final step. Its main objective will be to adequately describe the dome mechanical behaviour, by following two approaches.

The first one involves the formulation of analytical models, based on both limit (review of the Durand-Claye method, identification of statically admissible stress fields) and nonlinear elastic analysis (Aita et al., 2012; Aita et al., 2015; Aita et al., 2016a; Aita et al., 2016b). A basic input for analytical models is represented by the ideal surface that describes the dome geometry, obtainable by appropriately processing the results of its survey. Through limit analysis, it is possible to take account of the strength of the materials composing the structure; the nonlinear elastic model is also able to provide some indication on displacement and strain distributions.

The second approach consists in the implementation of a finite element model of the dome in order to accurately reproducing the actual load and constraint conditions. To this end, a highdensity survey of its actual geometry and materials is required.

Another purpose of the structural analysis is to find an adequate mechanical interpretation of cracks and damages, asymmetries and geometric irregularities of the dome, as shown by the survey. To this end, both an accurate survey of the crack pattern and the evaluation of deviation between the actual and ideal geometry are essential.

\subsection{An historical overview of the dome surveys and graphical representations available to date}

To the purposes of the present work, a detailed survey aimed to the structural analysis is necessary because of the absence of dome surveys characterized by high-density and precision.

Without being exhaustive, the status quo on the surveys of the Cathedral dome, from the most ancient ones up today is briefly reviewed in the following paragraph.

Accessibility issues have long hindered rigorous surveys of the dome, as well as its particular shape, which makes it difficult to define its geometrical configuration by means of discrete points. The first plan of the Cathedral known to us appears in the Siena notebook by Giuliano da Sangallo (Peroni, 1995b). The dome (Fig. 1) is represented in a qualitative way, within the space defined by the four cruciform pillars.

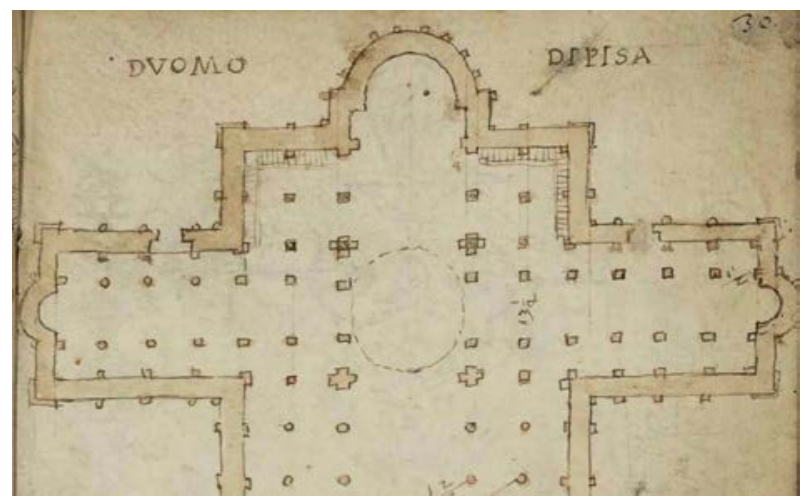

Figure 1. Detail from the Siena notebook by Giuliano da Sangallo with the planimetric representation of the dome.
In other ancient drawings the representation of the dome is completely omitted, as in the plan by Adriano dell'Oste depicting the presbytery (1595).

In the Theatrum Basilicae Pisanae by Giuseppe Martini (1705), the representation of the dome is rather remarkable in the beautiful planimetric and perspective engravings drawn by the Pisans Giuseppe and Francesco Melani. It is interesting to observe that the dome presents a nearly semicircular profile in the south elevation (Fig. 2), whereas the pointed profile of the dome is visible in the longitudinal section of the Cathedral (Fig. 3). The drawings here described are taken by the edition of 1878 (Martini \& Lejeal, 1878). It should be noted that they are measured in Roman palms.

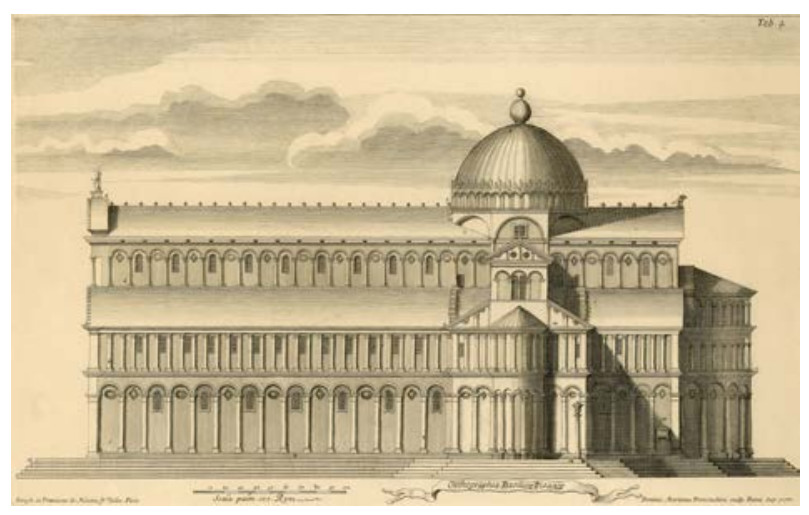

Figure 2. Orthographia Basilicae Pisanae by Giuseppe Martini (edited by Gustave Lejeal).

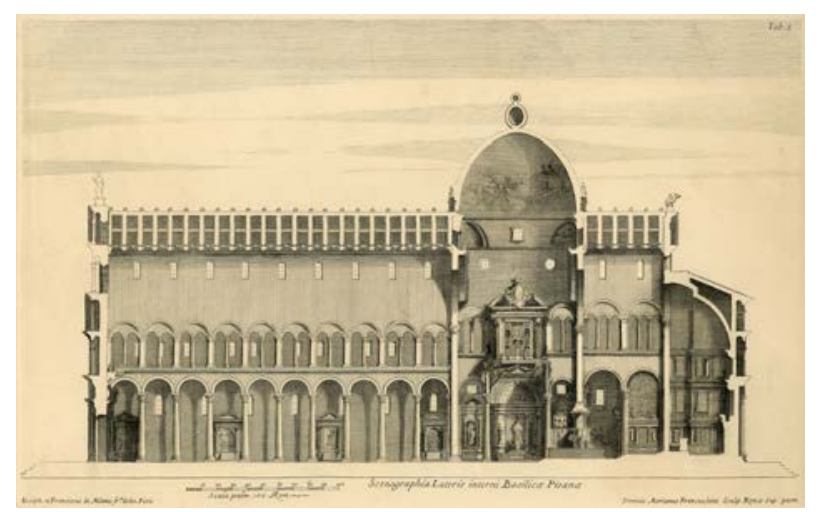

Figure 3. Scenographia Lateris interni Basilicae Pisanae by Giuseppe Martini (edited by Gustave Lejeal).

In Manesson Mallet's treatise on geometry (1702) the dome is depicted in an arbitrary manner in a trigonometry exercise inspired by the slope of the tower.

Among the dome representations, it is worthy to cite the plans and elevations reported in the Architecture civile by Carl Friedrich Wiebeking (1828). In the detail depicting the plan and longitudinal section, the representation of the dome is still qualitative, while reporting the scale in Parisian feet.

The surveys by Edward Cresy and George Ledwell Taylor (1829) stand out for the proven graphics expertise by the authors. The plan provides information about the covering of inner space, including the dome (Fig. 4). In the longitudinal section of the Cathedral (Fig. 5), the dome is shown in section, but some details are not correctly drawn, in particular the terminal ball and its connection to the dome. It is worthy to note 
that the Authors chose not to draw the dome in the elevation representing the apse.



Figure 4. Plan of the Cathedral by Edward Cresy and George Ledwell Taylor.

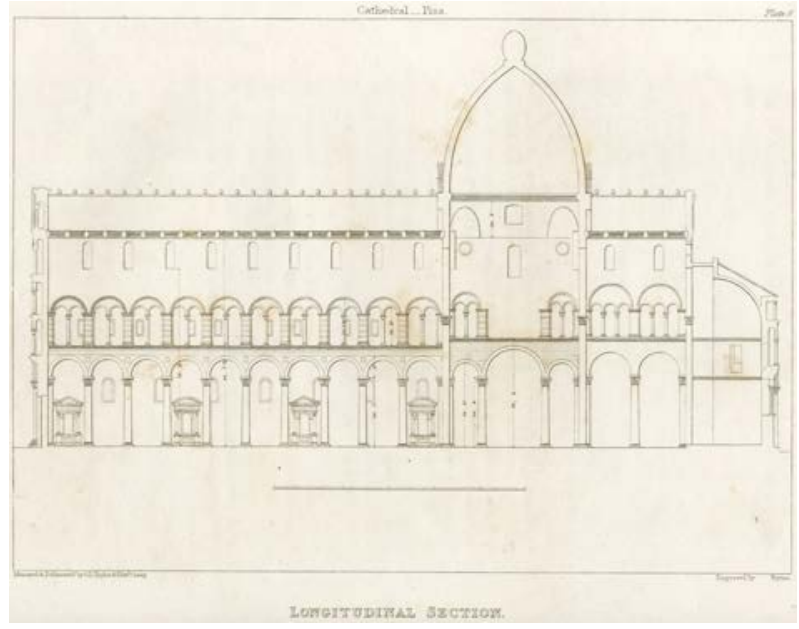

Figure 5. Longitudinal section of the Cathedral by Edward Cresy and George Ledwell Taylor (Plate 6).

According to Peroni (1995c), the first survey of the Cathedral meeting modern critical requirements was carried out by Georges Rohault de Fleury (1868). Despite a refinement of survey procedures, the dome remains a difficult object for survey. Its pointed profile is represented in the flank elevations and in the section of the nave towards the choir, with some uncertainties.

In a significant essay on the description of the Cathedral with a collection of engravings by Ladislaus Rupp and Carlo Gilio (probably dating back to 1825), the pointed profile of the dome is still drawn in a qualitative manner, e.g. in the elevazione geometrica della facciata (Fig. 6), without respecting the true proportions. Another table (Fig. 7) offers an interesting document on the situation before the restoration carried out by Sanpaolesi.

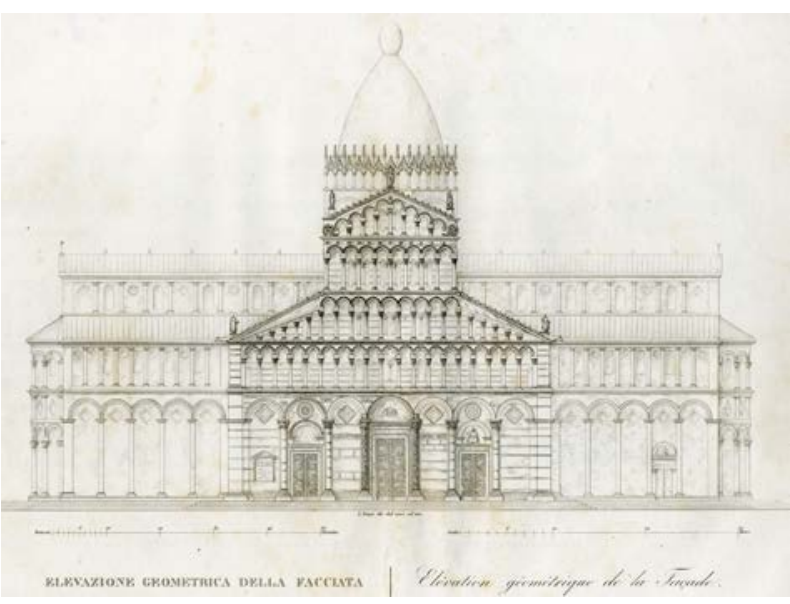

Figure 6. The elevation of the façade, with a qualitative representation of the dome by Ladislaus Rupp.

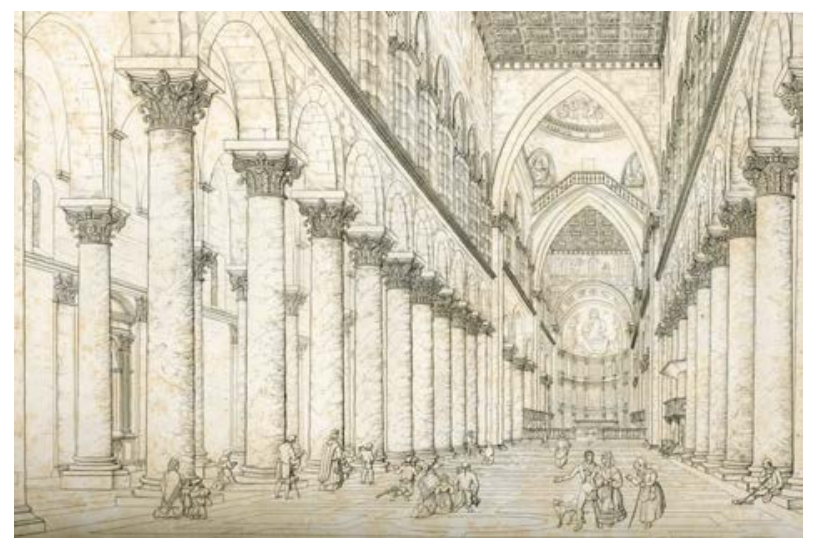

Figure 7. A perspective view of the interior of the Cathedral by Carlo Gilio. Detail.

The most complete and articulated survey of the Cathedral can be considered the one promoted by Sanpaolesi and executed by Piero Roselli, organized by the Istituto di restauro dei monumenti (University of Florence, 1970). This survey provides interesting information related to the dome profile, which is accurately represented in elevation and in section (Fig. 8). 



Figure 8. Dome representations (elevation, section) from the survey promoted by the Istituto di restauro dei monumenti (Florence). Details.

With reference to the structure and internal constitution of the dome, the surveys by Giulio Fontana (Sovrintendenza di Pisa), performed on occasion of the restoration promoted by Sanpaolesi (1959c), are undoubtedly of primary interest (Fig. 9).

These last two cited surveys will be subject to a comparison with the results obtained within the present research.

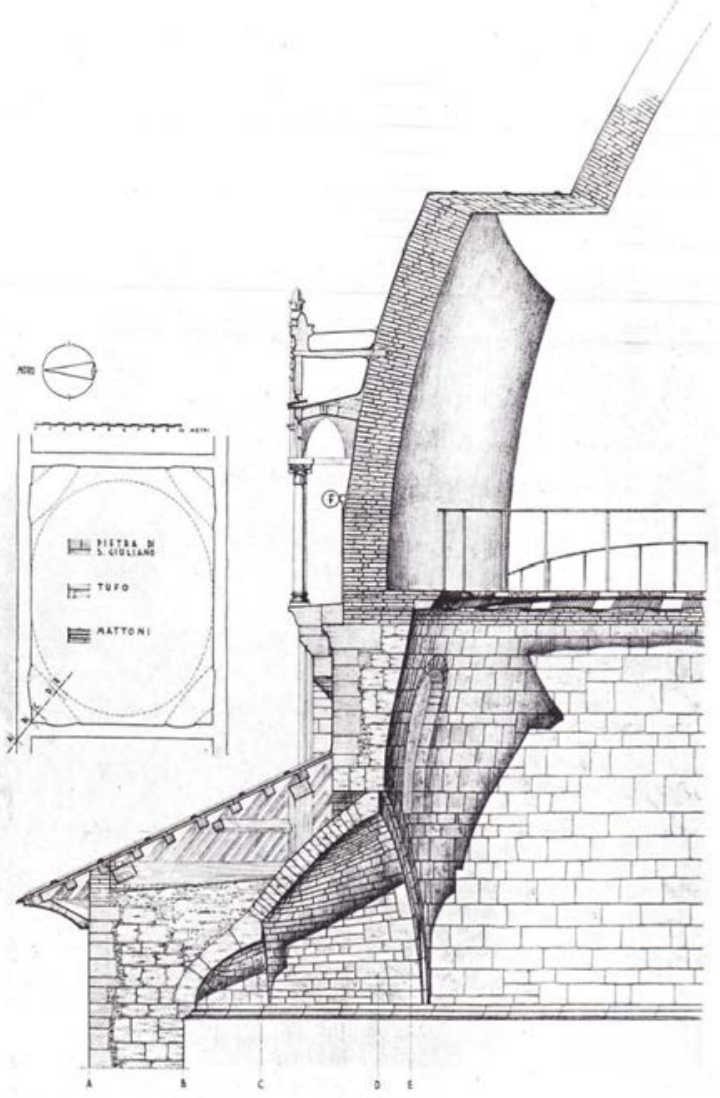

Figure 9. Section of the dome on the bisecting line of the plume, from the surveys by Giulio Fontana.

A number of other surveys will be omitted for the sake of brevity. It suffices to note here that a survey characterized by high density and adequate precision is not available as well as a $3 \mathrm{D}$ representation of the dome.

\subsection{Survey methods}

To date, three-dimensional architectural surveys mainly use two methodologies, i.e. range-based modelling and image-based modelling. The former exploits laser scanning to provide threedimensional point clouds, composed of millions dots in the same reference system. This point cloud model could represent the survey object geometry with a sub-centimetre accuracy (Guidi \& Remondino, 2012). The second one, through the integration of efficient computer vision algorithms such as Structure from Motion (SfM), Multi-View Stereo (MVS) with classic photogrammetry procedures, can provide both a geometric model and the radiometric information allowing model texturing (Bevilacqua, 2016; Remondino et al., 2014). Given the need to obtain a model of the dome that is able to provide both the strict definition of its geometry and the analysis of building materials, it was necessary to proceed with both surveying methods and integrate their results (Caroti et al., 2015; Robleda et al., 2016).

The point cloud model allowed to obtain the actual geometry and deduce the ideal surfaces, necessary in order to program 
structural analytical models and checking possible lacks of symmetry.

The opportunity to get quite close to the dome, together with the occlusion of the internal scaffolding during its staging, has led to provide distinct steps for the geometry survey:

1) Topographical survey of a support network, at ground level.

2) Laser scanning and photogrammetry of the intrados, at ground level.

3) Laser scanning and photogrammetry of the intrados, at matroneum level.

4) Topographical survey of an internal support network, at springer level.

5) Laser scanning and photogrammetry of the intrados, at springer level.

6) Topographical survey linking intrados and extrados.

7) Laser scanning of the extrados, on the scaffolding close by.

8) Laser scanning of the extrados, at ground level.

Completion of steps 1 to 3 took place prior to the staging of scaffolding. Steps 4 and 5 were completed during a temporary work stoppage, with the internal scaffolding at springer level.

Steps 6 to 8 have been carried out upon completion of the scaffolding.

As previously stated, while the scaffolding provided a privileged access point at the upper levels, it is intrinsically unstable and therefore unsuitable for a 1:50 (or better) survey. For this reason, the support survey carried out by total station is of the foremost importance. During its execution, measuring stations were consistently placed on firm spots, such as ground, matroneum floor and masonry landings along stair flights linking service doors at drum and springer level.

Points surveyed via total station act as either Ground Control Points (GCPs) or Control Points (CPs) in photogrammetry processing and point cloud registration.

As for laser scanning surveys, performed via Leica's P20 ScanStation with a point cloud density of about $70 \mathrm{pts} / \mathrm{cm}^{2}$ on average, scans at lower levels allowed to collect point clouds including both the area of interest, i.e. the dome, and portions closer to ground levels. These clouds have been orientated using ground-level benchmarks, featuring higher reliability than those at dome level. Registration of clouds collected in close proximity to the dome used both dome-level benchmarks and cloud-matching algorithms with previously registered clouds. Photogrammetric surveying, carried out by means of Nikon's D700 DSLR fitted with a 50mm lens at dome level and a $85 \mathrm{~mm}$ lens at matroneum and ground levels, yielded a mean Ground Sampling Distance $(\mathrm{GSD})=3 \mathrm{~mm}$. It has been subjected to image processing via SfM algorithms, granting an overlap $\geq 70 \%$. Collection of images from different distances $(12 \mathrm{~m}$ at dome drum level, $45 \mathrm{~m}$ at ground level) allowed for model checking and increased rigidity. Bundle adjustment with 10 GCPs resulted in standard deviation $=2 \mathrm{~mm}$ on $15 \mathrm{CPs}$.

The above allows to state that images were correctly orientated in the relevant reference system, and therefore they can be used in texturing laser scanning models registered in the same reference system.

The point cloud models obtained by surveys have particular computational limitations. In fact, it is not possible to compute the physical behavior of a point cloud model. It's necessary to transform the point cloud model into a polygonal surface one. Starting from the cloud model, a simplified mesh model suitable for finite element calculation was then defined (Caroti et al., 2012; Caroti \& De Falco, 2003; Caroti \& Fangi, 2004; Visintini \& Spangher, 2013).
The transition from point cloud model to polygonal surface model is definable in all respects as an operation of "retopology", i.e. the quantitative and qualitative information in the point model are converted to obtain a triangular or quadrangular representation of the polygonal surface. These conversion processes can introduce geometric variations in the model, whose extent can be checked via software to match allowed tolerances and the purpose of the survey itself.

Procedures for a fairly expeditious reconstruction of the rendering of the status quo of a building starting from point cloud data are, to date, well known: starting from views in orthogonal projection of the point cloud, sections and elevations are obtained in both horizontal and vertical planes. These are exported in scale as seen on the screen (screenshot) in CAD software, through which draftsmen, even if lacking any experience in point cloud processing, are able to digitize them and render the final 2-D product.

This type of procedure may be used to generate mesh models as a first approximation, but shows significant limitations. In fact, such processing is based on predetermined, smooth, ideal geometry, which may not reflect the actual geometry of the building: rendering based on ideal lines and planes may result in the unintentional correction of the situation of the structure, in terms of displacement and/or distortion.

Another method is to work directly on the point cloud and from this generate a dense contour rendering that extrapolates samples of 3-D points on limited areas from the model analyzed in section. In this case, unlike the previous one, the final product is in 3-D, thus allowing investigation of features such as structural dimensions, out-of-plumb conditions, horizontality etc. However, the discretization introduced by this type of modelling may alter reality, e.g. distorting the correct geometry of structural elements or the correct position and size of their connections.

The present work has instead focused on "meshing", i.e. the transition from the raw cloud of 3D points produced by the sensor to a grid of polygons connected to each other, whose vertices coincide with the measured points (mesh). The point cloud is an unstructured cloud consisting of spatially unorganized points.

Through a meshing software, cloud errors due to noise in the acquisition phase have been corrected. The number of points has also been reduced to a specific density on a curved surface, also converting point objects in vertices of polygon mesh object, thus changing from a point cloud into a mesh model.

A high-density polygonal surface model (henceforth referred as High poly) has then been produced with a representation that allows the model to be described by means of the relations between these vertices: geometric information (coordinates $\mathrm{x}, \mathrm{y}$, z), edges and faces.

Ambiguous relationships among these elements are not allowed: for this reason, specific tools for the correction of topological errors to optimize the model are used. The model validation requires a vertex-to-vertex connection between contiguous meshes.

Upon merging the various portions of the different dome and drum parts to create a single polygonal mesh, residual errors in the model (topological errors, gaps and surface noise) have been corrected.

A low-density polygonal model (Low poly) was derived by the High poly model, making the appropriate changes to be compatible (computable) with the finite elements software. This provided an effective support for structural computation, while keeping the formal and geometric characteristics of High poly. 
Some of the main changes arose from the following requirements:

- Handling via structural computation software. For this purpose, a decimation of the number of polygons was achieved by imposing triangular meshes with side length $<50 \mathrm{~cm}$, setting a minimum number of triangles and keeping a larger number of elements in the zones with a lower radius of curvature. Models with different number of polygons were created, all the while keeping the right balance between computational simplicity and structural coherence, i.e. without oversimplifying the model obtained with the high-resolution survey.

- Removal of all non-structural elements such as cornices, friezes, ornaments, ets. certainly useful for architectural completeness but unnecessary in a structural approach.

\section{RESULTS AND DISCUSSION}

The above-mentioned processing provided three kinds of output:

\section{- $\quad$ High poly texturized model \\ - $\quad$ Low poly model \\ - $\quad$ Sections and plans}

The High poly texturized model provides a geometric description of the dome, keeping the same spatial density and accuracy of the laser scanning survey and the radiometric quality of the high-resolution photographic campaign (Fig. 10). This representation directly returns the three-dimensionality of the actual state of the architecture, allowing its critical reading in a virtual environment.

On the other hand, the exceeding complexity of this model prevents its use in structural computation software.

To this end, Low poly model (Fig. 11) has instead been optimized for use in finite elements analysis. As the extrados survey is not completed yet, the Low poly model currently represents just the intrados surface. When the complete model will be available, it will allow detection of the mean surface and dome thickness variations, which on turn will be added to the final model, including also information on thickness and materials required for structural computations.

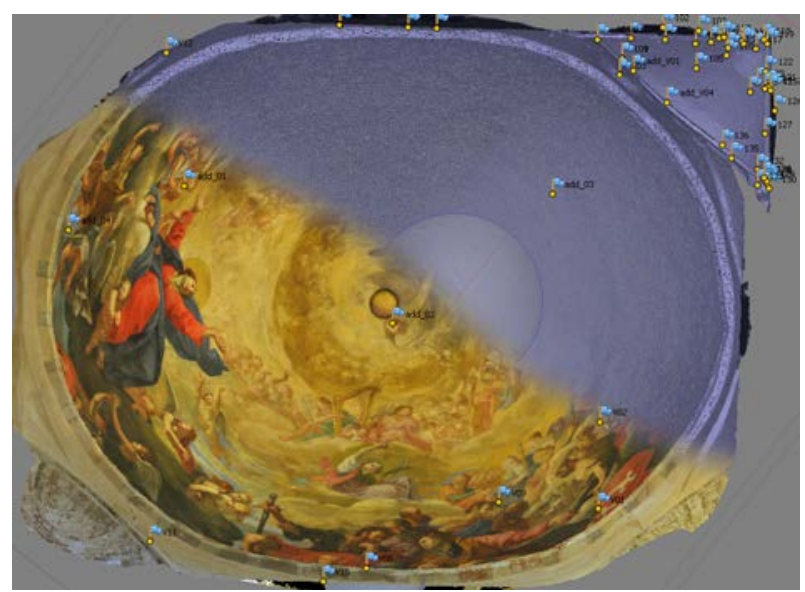

Figure 10. High poly texturized model.

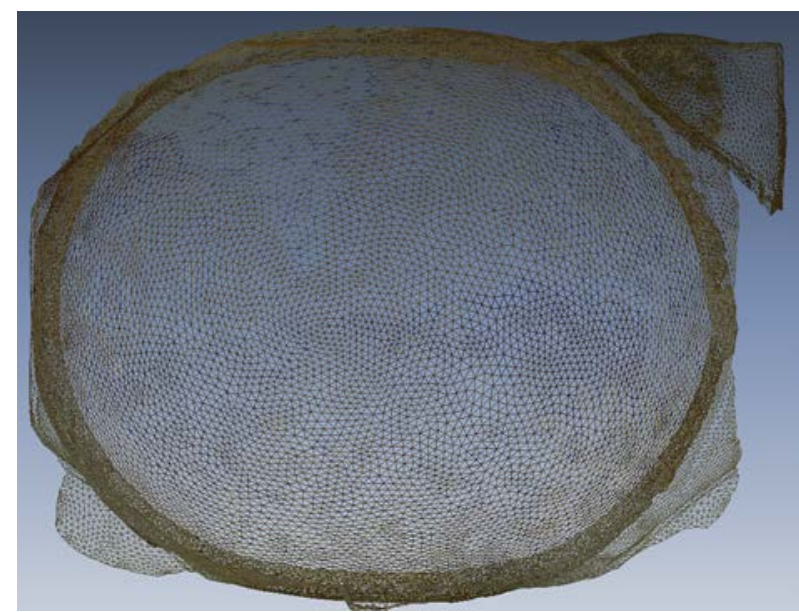

Figure 11. Low poly model.

The High poly model provided sections and plans which allowed precision checks of the graphical documents related to archival surveys.

In particular, a meridian section along a parallel to the transect axis matched nicely a corresponding section referring to the 1970 survey (Fig. 12).

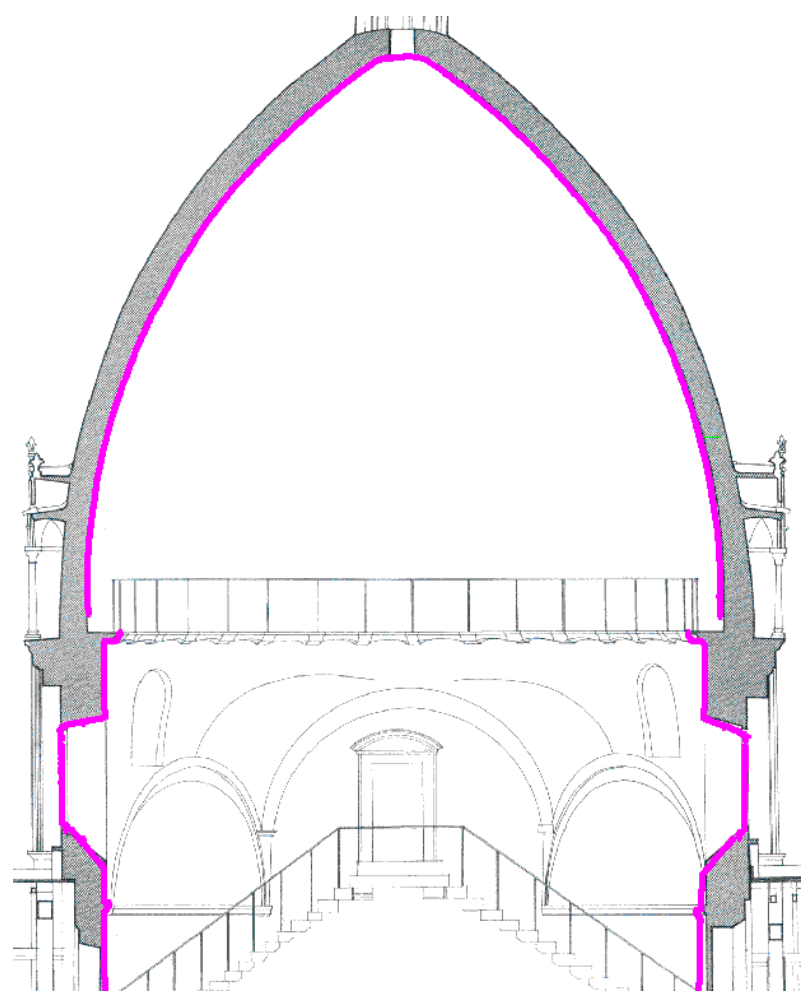

Figure 12. Section from current survey (pink) and from the survey promoted by the Istituto di restauro dei monumenti (Florence) (black).

On the other hand, the latter survey lacked any plans related to the dome shape.

Plans have then been checked against the most recent available documents, e.g. the 1959 Fontana survey (Figure 13). In this case, overall matching was good, save for the oval squeezing factor along the shorter semiaxis.

An interesting fact, testifying once more the strictness with which the masonry workers of the time were able to match draft geometries, is in that the current survey shows that the common 
point between the symmetry axes of main nave and transect (computed from ground level elements) and the ground-level projection of the center of the dome (i.e. the tangent point between the top of the dome and an horizontal plane) differ by only $5 \mathrm{~cm}$, with an altitude difference of about $45 \mathrm{~m}$.

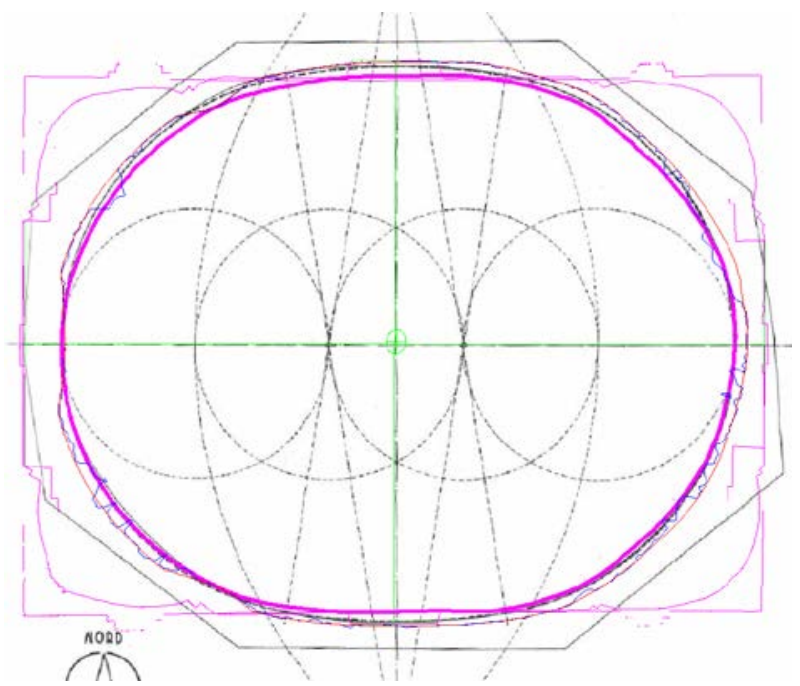

Figure 13. Plans from current survey (pink) and from Fontana survey (black).

\section{CONCLUSIONS}

A preliminary study has been presented on the reconstruction of the actual shape and constituting materials of the dome of Pisa Cathedral, by discussing the first results obtained through range-based (laser scanning) and image-based (3D Photogrammetry) survey methodologies. A suitable integration has been performed between the two survey methods.

Point-cloud models, obtained by high-precision laser-scanner surveys, allow obtaining the dome geometry and deducing the corresponding ideal surfaces that are needed in order to perform subsequent structural analyses, and check possible lacks of symmetry as well. Given the computational limitations of the point cloud model, an adequate "meshing" has to be studied. In this regard, starting from the cloud model, a simplified mesh model suitable for finite element calculation has been defined. As a first noticeable result, survey showed that all meridian sections of the intrados surface are approximately circular pointed arcs.

As proved by the historical overview of the dome surveys, it is worthy to note that a survey characterized by high density and adequate precision was not available as well as a 3D representation of the dome.

The next step of the present research will be addressed to an accurate investigation of the dome structural response through analytical models (Durand-Claye's method and nonlinear elastic analysis). In this regard, the ideal intrados and extrados surfaces, and-the ideal mean surface as well, will be suitably defined. The analytical models will be validated through the implementation of a finite element model of the dome able to accurately describing the actual load and constraint conditions.

\section{REFERENCES}

Aita, D., Barsotti, R., Bennati, S., 2016a. Explicit solutions for depressed masonry arches loaded until collapse - Part I: a one- dimensional nonlinear elastic model, in Meccanica, Print ISSN 0025-6455, Online ISSN 1572-9648, pp. 1-13, DOI: 10.1007/s11012-016-0420-4.

Aita, D., Barsotti, R., Bennati, S., 2016b. Explicit solutions for depressed masonry arches loaded until collapse - Part II: a solution method for statically indeterminate systems, in Meccanica, Print ISSN 0025-6455, Online ISSN 1572-9648, pp. 1-14, DOI: 10.1007/s11012-016-0440-0.

Aita, D., Barsotti, R., Bennati, S., 2015. Notes on Limit and Nonlinear Elastic Analyses of Masonry Arches. In Aita D., Pedemonte O., Williams K. (eds.), Masonry Structures: Between Mechanics and Architecture, Birkhäuser, Basel, Print ISBN 978-3-319-13002-6, Online ISBN 978-3-319-13003-3, pp. 237-264, DOI: 10.007/978-3-319-13003-3_9.

Aita, D., Barsotti, R., Bennati, S., 2012. Equilibrium of Pointed, Circular, and Elliptical Masonry Arches Bearing Vertical Walls, in Journal of Structural Engineering, Vol. 138 (7), Print ISSN 0733-9445, Online ISSN 1943-541X, pp. 880-888, DOI: 10.1061/(ASCE)ST.1943-541X.0000522.

Bevilacqua, M.G., Caroti, G., Martínez-Espejo Zaragoza, I., Piemonte, A., 2016. Frescoed Vaults: Accuracy Controlled Simplified Methodology for Planar Development of ThreeDimensional Textured Models. Remote Sens. MDPI, Suiza, 8, 239. 2016. pp. 1-16. doi:10.3390/rs8030239

Caroti, G., Martínez-Espejo Zaragoza, I., Piemonte, A., 2015a. Range and image based modelling: A way for frescoed vault texturing optimization, in International Archives of the Photogrammetry, Remote Sensing and Spatial Information Sciences - ISPRS Archives, 40 (5W4), pp. 285-290, DOI: 10.5194/isprsarchives-XL-5-W4-285-2015.

Caroti, G., Martínez-Espejo Zaragoza, I., Piemonte, A., 2015b. Accuracy assessment in structure from motion 3D reconstruction from UAV-born images: The influence of the data processing methods, in International Archives of the Photogrammetry, Remote Sensing and Spatial Information Sciences - ISPRS Archives, 40 (1W4), pp. 103-109, DOI: 10.5194/isprsarchives-XL-1-W4-103-2015.

Caroti, G., Franconi, A., Piemonte, A., 2012. Metodologia di elaborazione dati laser scanner per la generazione di modelli utili al calcolo strutturale, in Proceedings of 16a Conferenza Nazionale ASITA, pp.383-390, ISBN 978-88-903132-7-1.

Caroti, G., Fangi, G., 2004. Il rilievo della volta interna del Battistero in S.Maria del Fiore e le chiese fiorentine del duecento e del trecento nella città delle fabbriche arnolfiane, p.p. 145-148, ed. Alinea, Firenze, ISBN: 8881258110.

Caroti, G., De Falco, A., 2003. Geometric survey for the structural assessment of the architectural heritage: the case of the Baptistery of S. Giovanni e Reparata in Lucca. in International Archives of the Photogrammetry, Remote Sensing and Spatial Information Sciences - ISPRS Archives, vol. XXXIV, p. 111-116, ISSN: 1682-1750

Cresy, E., Taylor, G. L., 1829. Architecture of the Middle Ages in Italy: illustrated by views, plans, elevations, sections, and details, of the Cathedral, Baptistery, Leaning Tower or Campanile, and Campo Santo, at Pisa, from Drawings and Measurements Taken in the Year 1817, London. 
Dell’Oste, A., 1595. Carte Lupi 10.IV, Archivio di Stato, Pisa.

Fleury, R. de, 1866. Les Monuments de Pise au Moyen-Age, 2 voll., Paris (Atlas, Paris 1868).

Guidi, G., Remondino, F., 2012. 3D Modelling from Real Data, in Modeling and Simulation in Engineering, ISBN 978-953-510012-6, pp. 69-102, DOI: 10.5772/30323.

Laefer, D.F. , Carr, H. , Morrish, S. , Kalkan, E., 2006. Opportunities and impediments to the use of three-dimensional laser scanning for adjacent excavations. In Proceeding GeoCongress 2006: Geotechnical Engineering in the Information Technology Age. Vol. 2006, p. 78. DOI:10.1061/40803(187)78

Martini, G., 1705. Theatrum basilicae pisanae, in quo praecipuae illius partes enarrationibus iconibusque ostenduntur, cura et studio Josephi Martinii ejusdem Basilicae Canonici et J.S., De Rubeis, Roma.

Martini, G., Lejeal, G., 1878. Les grands édifices de Pise: dôme, baptistère, campo-santo, tour penchée: 40 gravures tirées avec les cuivres originaux du Theatrum basilicae Pisanae de Martini / texte extrait de Martini et notes par G. Lejeal, Paris: A. Lévy.

Manesson Mallet, A., 1702. La Geometrie pratique: Tome second. Contenant la trigonometrie ou la mesure des distances par les instrumens geometriques ..., Paris: Anisson directeur de l'Imprimerie Royale.

Peroni, A., 1995a. Architettura e decorazione. In: Peroni Adriano (ed.), Il Duomo di Pisa, Collana Mirabilia Italiae (diretta da Salvatore Settis), Franco Cosimo Panini Editore, Modena, pp.68-69.

Peroni, A., 1995b. Architettura e decorazione. In: Peroni Adriano (ed.), Il Duomo di Pisa, Collana Mirabilia Italiae (diretta da Salvatore Settis), Franco Cosimo Panini Editore, Modena, p 21.

Peroni, A., 1995c. Architettura e decorazione. In: Peroni Adriano (ed.), Il Duomo di Pisa, Collana Mirabilia Italiae (diretta da Salvatore Settis), Franco Cosimo Panini Editore, Modena, p. 23.

Remondino, F., Spera, M.G., Nocerino, E., Menna, F., Nex, F., 2014. State of the art in high density image matching, in The Photogrammetric Record, 29(146), pp. 144-166, DOI: 10.1111/phor.12063.

Robleda, P.G., Caroti, G., Martínez-Espejo, Z.I., Piemonte, A., 2016. Computational vision in UV-Mapping of textured meshes coming from photogrammetric recovery: Unwrapping frescoed vaults, in International Archives of the Photogrammetry, Remote Sensing and Spatial Information Sciences - ISPRS Archives, 41, pp. 391-398, DOI: 10.5194/isprsarchives-XLIB5-391-2016.

Salmi, M., 1938. La genesi del Duomo di Pisa, in Bollettino d’Arte, s. III, vol. XXXIII, pp. 149-161.

Sanpaolesi, P., 1959a. Il restauro delle strutture della cupola della Cattedrale di Pisa, in Bollettino d'Arte, Anno XLIV, fasc. III, luglio-settembre, Serie IV, p. 202.
Sanpaolesi, P., 1959b. Il restauro delle strutture della cupola della Cattedrale di Pisa, in Bollettino d'Arte, Anno XLIV, fasc. III, luglio-settembre, Serie IV, pp. 199-230.

Sanpaolesi, P., 1959c. Il restauro delle strutture della cupola della Cattedrale di Pisa, in Bollettino d'Arte, Anno XLIV, fasc. III, luglio-settembre, Serie IV, pp. 207.

Supino, I. B., 1913. La costruzione del Duomo di Pisa : memoria letta il 26 febbraio 1913 alla Classe di scienze morali della R. Accademia delle scienze dell'Istituto di Bologna, Bologna: Tip. Gamberini e Parmeggiani.

Smith, C., 1984. East or West in 11th-Century Pisan Culture. the Dome of the Cathedral and Its Western Counterparts, in Journal of the Society of Architectural Historians, XLIII, pp. 195-208.

Visintini, D., Spangher, A., 2013. Rilevamento laser scanning, modello della superficie (DSM) e modello per il metodo agli elementi finiti (FEM) di una struttura, Atti della 17a Conferenza Nazionale ASITA, 1287-1294.

Wiebking, C. F. de, 1828. Architecture civile théorique et pratique des édifices anciens et modernes les plus remarquables et de leurs dessins exacts, Munich.

Descrizione del Duomo di Pisa, probably dating back to 1825. (Fondo Comune di Pisa, Legato Bellini-Pietri, Museo civico; Biblioteca di Storia delle Arti, University of Pisa).

Il Duomo di Pisa / rilievo a cura dell'Istituto di restauro dei monumenti, 1970. Università degli studi Istituto di restauro dei monumenti Firenze, Nistri-Lischi, Pisa. 